\title{
Wspótczesne wyzwania technologiczne a zarządzanie projektami w organizacjach
}

\author{
Dr hab. inż. Seweryn Spałek, prof. PŚ \\ Politechnika Śląska, Wydział Organizacji i Zarządzania
}

\section{Wprowadzenie}

Zarządzanie projektami w organizacjach podlega nieustannym zmianom związanym zarówno z wyzwaniami mającymi swoje źródła wewnątrz środowiska projektowego, jak i z wyzwaniami w otoczeniu tego środowiska ${ }^{1}$. Do pierwszych należą aspekty łączące się z szeroko pojętą potrzebą doskonalenia działalności projektowej organizacji ${ }^{2}$. Może się ona przejawiać jako zamiar podnoszenia stopnia dojrzałości projektowej w obszarach metod i narzędzi, zasobów ludzkich, środowiska projektowego oraz zarządzania wiedzą ${ }^{3}$. Cechą charakterystyczną działań podejmowanych w tym zakresie jest potrzeba zwiększania efektywności i skuteczności zarządzania ${ }^{4}$. Czynniki zewnętrzne natomiast przyczyniają się do powstawania wyzwań, na które organizacja stara się znaleźć właściwą odpowiedź ${ }^{5}$. Do takich sytuacji dochodziło już w przeszłości. Przykładowo: w latach dziewięćdziesiątych ubiegłego stulecia na wyzwanie związane z gwałtownym wzrostem liczby projektów odpowiedzią

1 S. Cyfert, Strategiczna odnowa przedsiębiorstwa, [w:] G. Bełz, S. Cyfert (red.), Strategiczna i organizacyjna odnowa przedsiębiorstwa, Wydawnictwo Uniwersytetu Ekonomicznego we Wrocławiu, Wroctaw 2017. s. 19-34; M. Trocki, Miejsce i rola projektów w zarzq̨dzaniu, [w:] M. Trocki (red.), Społeczna odpowiedzialność działalności projektowej, Oficyna Wydawnicza SGH - Szkoła Główna Handlowa w Warszawie, Warszawa 2019, s. 9-21.

2 A. Stabryła (red.), Doskonalenie struktur organizacyjnych przedsiębiorstw w gospodarce opartej na wiedzy, Wydawnictwo C.H. Beck, Warszawa 2009; P. Cabała (red.), Metody doskonalenia procesów zarzq̨dzania projektami w organizacji, Wydawnictwo Difin, Warszawa 2016.

3 S. Spatek, Dojrzałość przedsiębiorstwa w zarzq̨dzaniu projektami, Wydawnictwo Politechniki Śląskiej, Gliwice 2013.

4 M. Dolata, The Sources of Competitive Advantage from the Perspective of Project Management - Results of Empirical Studies, „Management-Poland” 2019, vol. 23, no. 1, s. 75-89; M. Romanowska, Effectiveness of Reorganization of an Enterprise Operating in a Globalized Sector, „Transformations in Business and Economics” 2009, vol. 8, no. 3, suppl. B, s. 83-93; K.R. Wysocki, R. McGary, Efektywne zarzqdzanie projektami, Wydawnictwo Helion, Gliwice 2005.

5 T.H.D. Nguyen i wsp., External Stakeholder Strategic Actions in Projects: A Multi-Case Study, „International Journal of Project Management” 2019, vol. 37, no. 1, s. 176-191. 
była koncepcja biura zarządzania projektami ${ }^{6}$. $Z$ kolei na początku obecnego stulecia nastąpił znaczny wzrost dynamiki zmienności wymagań klientów, wskutek czego wprowadzono zwinne zarządzanie projektami (Agile Project Management - APM $)^{7}$. Ta tendencja utrzymuje się również obecnie, przez co APM upowszechnia się w praktyce gospodarczej obok tradycyjnego podejścia do zarządzania projektami ${ }^{8}$.

Wprowadzanie nowych technologii wpływało również na zarządzanie projektami w organizacjach. Do najczęściej wymienianych należy upowszechnienie się technologii informacyjnych ${ }^{9}$. W początkowym okresie technologie te przyczyniały się głównie do dalszego doskonalenia działalności projektowej przedsiębiorstw w zarządzaniu czasem, kosztami czy też zakresem projektu10. Powodowały też ponowne upowszechnianie się metod, które wraz ze wzrostem stopnia złożoności projektów zostały zarzucone jako zbyt czasochłonne. Przykładowo: dzięki zwiększeniu się mocy obliczeniowej komputerów osobistych powstały aplikacje wspierające możliwość wykorzystania metody ścieżek krytycznych (Critical Path Method) w przypadku bardzo złożonych przedsięwzięć ${ }^{11}$. Również metoda wartości uzyskanej (Earned Value Method) zyskała znacząco na popularności dzięki możliwościom, jakie dają nowoczesne technologie informatyczne ${ }^{12}$.

Ponadto wzrost możliwości przetwarzania dużych zbiorów danych (Big Data) umożliwił między innymi lepsze wykorzystanie wiedzy zgromadzonej ze zrealizowanych przedsięwzięć w nowych projektach już na etapie ich planowaniais Należy jednak podkreślić, że nowe technologie to nie tylko szanse dla organizacji,

6 P. Wyrozębski, Biuro zarzq̨dzania projektami, Polskie Wydawnictwo Ekonomiczne, Warszawa 2019.

7 R.F. Bordley, J.M. Keisler, T. M. Logan, Managing Projects with Uncertain Deadlines, „European Journal of Operational Research" 2019, vol. 274, no. 1, s. 291-302.

8 S. Spatek, Traditional vs. Modern Project Management Methods. Theory and Practice, „Smart and Efficient Economy: Preparation for the Future Innovative Economy" 2016, s. 499-506.

9 Y. Kang, W.J. O'Brien, S.P. Mulva, Value of It: Indirect Impact of It on Construction Project Performance Via Best Practices, „Automation in Construction” 2013, no. 35, s. 383-396.

10 J. Liu, F. Wei, The Application of Project Management in Aero-Engine Developing Project, [w:] H. Wang, K. Takahashi (red.), ICIM2012: Proceedings of the Eleventh International Conference on Industrial Management, Japan Industrial Management Association, Tokyo 2012, s. 245-248.

11 K. Kim, J.M. de la Garza, Evaluation of the Resource-Constrained Critical Path Method Algorithms, „Journal of Construction Engineering and Management-Asce” 2005, vol. 131, no. 5, s. 522-532.

12 M. Wauters, M. Vanhoucke, A Comparative Study of Artificial Intelligence Methods for Project Duration Forecasting, „Expert Systems with Applications” 2016, no. 46, s. 249-261.

13 A. Alharthi, V. Krotov, M. Bowman, Addressing Barriers to Big Data, „Business Horizons” 2017, vol. 60, no. 3, s. 285-292. 
ale i zagrożenia. Dlatego też stojące przed organizacjami wyzwania związane z nowymi technologiami trzeba rozpatrywać zarówno w kontekście możliwości, jakie oferują, jak i potencjalnych skutków negatywnych, jakie może wywołać w organizacji ich zastosowanie ${ }^{14}$.

Należy zauważyć, że o ile w literaturze naukowej można znaleźć przykłady rozważań dotyczących relacji nowoczesnych technologii do różnych sfer działalności organizacji ${ }^{15}$, o tyle występuje znaczący niedostatek w podejmowaniu tej problematyki w odniesieniu do obszaru zarządzania projektami ${ }^{16}$. Rodzi się następujące pytanie badawcze: „Które ze współczesnych technologii mogą implikować szczególne wyzwania dla zarządzania projektami w organizacjach?”.

\section{Badania empiryczne}

W celu udzielenia odpowiedzi na postawione pytanie badawcze przeprowadzono międzynarodowe badania empiryczne w okresie styczeń - luty 2019 roku. Badania ankietowe miały charakter ilościowy, oparty na próbie celowej. Ankieta została skierowana do osób zajmujących się zarządzaniem projektami w organizacjach. Kwestionariusz online utworzony został na podstawie systemu bazodanowego zbudowanego w ramach uprzednich badań autora, sfinansowanych przez Narodowe Centrum Nauki ${ }^{17}$.

\section{Próba badawcza}

Zaproszenie do badania zostało rozesłane do potencjalnych respondentów z wykorzystaniem bazy pozyskanej podczas uprzednich badań autora oraz z wykorzystaniem organizacji zrzeszających profesjonalistów z zakresu zarządzania projektami (Project Management Institute oraz International Project Management Association). Jako kryteria udziału respondentów w badaniu przyjęto: doświadczenie w realizacji projektów oraz doświadczenie w pracy w zespole projektowym (członek zespołu lub kierownik projektu). W wyniku podjętego wysiłku otrzymano 312 wypełnionych ankiet, z czego 264 kwalifikowały się do dalszej analizy danych

14 V. Vadhanasin, S. Ratanakuakangwan, K. Santivejkul, Social Media in Project Communication Management - a Conceptual Framework, „Advanced Science Letters” 2017, vol. 23, no. 1, s. $581-584$.

15 M.J.F.F. Ahsan, S.K. Herath, Adoption of E-Commerce in Small and Medium Enterprises: With Special Reference to the Sri Lanka-Based Apparel Industry, „International Journal of Management and Enterprise Development" 2006, vol. 3, no. 6, s. 579-598.

16 C. Besner, B. Hobbs, Discriminating Contexts and Project Management Best Practices on Innovative and Noninnovative Projects, „Project Management Journal” 2008, no. 39, s. S123-S134.

17 Projekt badawczy NCN o numerze N N504678740. 
(usunięto m.in. duplikaty, ankiety niewypełnione w całości oraz niespełniające założonych kryteriów). Największą liczbę respondentów (196) stanowili kierownicy projektów, natomiast pozostałe $26 \%$ to członkowie zespołu projektowego. Najwięcej, tj. 183 respondentów, miało 6-10 lat doświadczenia w projektach. Natomiast osoby mające 1-5 oraz powyżej 10 lat doświadczenia tworzyły zbliżone liczbowo zbiory, odpowiednio 42 osoby i 39 osób. Strukturę próby badawczej przedstawia tabela 1 .

Tabela 1. Struktura próby badawczej

\begin{tabular}{|l|r|r|}
\hline \multicolumn{1}{|c|}{ Respondenci } & Liczba & Procent \\
\hline Kierownik projektu & 196 & $74 \%$ \\
\hline Członek zespołu projektowego & 68 & $26 \%$ \\
\hline Razem & 264 & $100 \%$ \\
\hline & & \\
\hline Liczba lat doświadczenia w projektach & & \\
\hline $1-5$ & 42 & $16 \%$ \\
\hline $6-10$ & 183 & $69 \%$ \\
\hline Powyżej 10 & 39 & $15 \%$ \\
\hline Razem & 264 & $100 \%$ \\
\hline
\end{tabular}

Źródło: badania własne.

\section{Kwestionariusz}

Kwestionariusz ankiety składał się z dwóch części. Część pierwsza zawierała metryczkę dotyczącą respondentów, tj. ich doświadczenia i roli w projektach oraz typu realizowanych projektów. Część druga zbudowana była z pytań związanych z problematyką badawczą. Pytania dotyczyły w szczególności identyfikacji technologii mających obecnie największy wpływ na projekty, co do których istnieje największa niewiedza na temat sposobu wpływu na projekt oraz próby określenia wpływu zidentyfikowanych technologii na projekt. Pytania miały formę zamkniętą. Odpowiedzi na część pytań zawartych w kwestionariuszu ankietowani udzielali na podstawie pięciostopniowej skali Likerta (rzetelność przyjętej skali została potwierdzona przez wskaźnik Alfa Cronbacha, który wyniósł 0,82).

\section{Wyniki badań}

Dane uzyskane z 264 kwestionariuszy dotyczyły najczęściej projektów produkcyjnych (114), z czego 67 stanowiły projekty rozwoju nowych produktów (New Product Development - NPD). Kolejne były projekty informatyczne i budowlane, odpowiednio 56 przypadków i 52 przypadki. Pozostałe typy projektów stanowiły 42 przypadki (tabela 2 ). 
Tabela 2. Typologia badanych projektów

\begin{tabular}{|l|c|c|}
\hline \multicolumn{1}{|c|}{ Typ projektów } & Liczba & Procent \\
\hline Informatyczne & 56 & $21 \%$ \\
\hline Produkcyjne (w tym NPD) & $114(67)$ & $43 \%$ \\
\hline Budowlane & 52 & $20 \%$ \\
\hline Pozostate & 42 & $16 \%$ \\
\hline Razem & 264 & $100 \%$ \\
\hline
\end{tabular}

Źródło: badania własne.

W związku ze stosunkowo mało liczną próbą badawczą, szczególnie w odniesieniu do projektów danego typu, zdecydowano się na zaprezentowanie wyników badań w ujęciu statystyk opisowych.

W wyniku przeprowadzonej analizy uzyskanych danych (rysunek 1) stwierdzono, że zdaniem respondentów obecnie największy wpływ na projekty mają technologie związane z mediami społecznościowymi (T-MS) (78\% wskazań). Na drugim miejscu uplasowały się technologie związane z Przemysłem 4.0 (T-4.0), które wskazało prawie dwie trzecie ankietowanych. Na pozostałe technologie zwróciło uwagę $28 \%$ badanych.

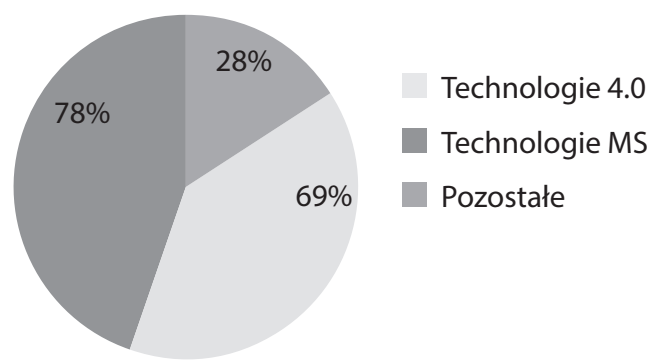

Rysunek 1. Technologie mające obecnie największy wpływ na działalność projektową

Źródto: badania własne.

Analizując siłę wpływu dwóch najczęściej wskazywanych technologii (T-MS i T-4.0), należy zauważyć znaczne zróżnicowanie w zależności od typu projektu i rodzaju technologii. I tak dla technologii związanych z mediami społecznościowymi (rysunek 2) zaobserwowano, że największy wpływ mają one na projekty informatyczne (średnio 3,5), a następnie na projekty produkcyjne (średnio 3,3) i budowlane (średnio 3,1). Wśród wskazań o dużym i znaczącym wpływie dominowały również projekty informatyczne (sumarycznie $54 \%$ wskazań), kolejne były produkcyjne (42\%) i budowlane (32\%). Pozostałe typy projektów uplasowały się z najniższym wpływem średnim - na poziomie 2,9. Duży i znaczący wpływ technologii MS był na sumarycznym poziomie $24 \%$. 


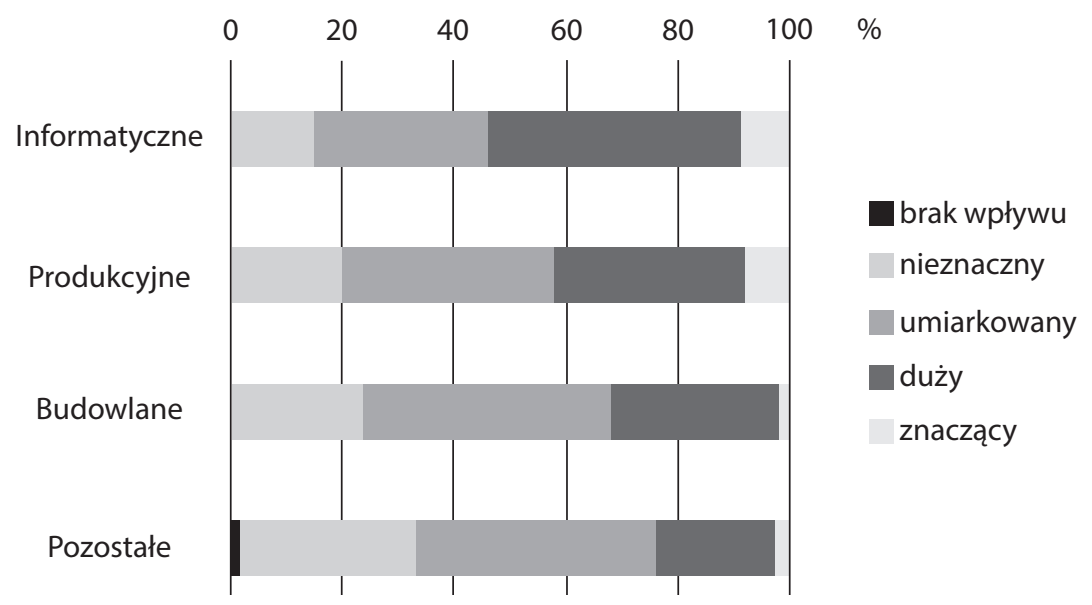

Rysunek 2. Wpływ technologii związanych z mediami społecznościowymi na działalność projektową według typu projektu

Źródto: badania własne.

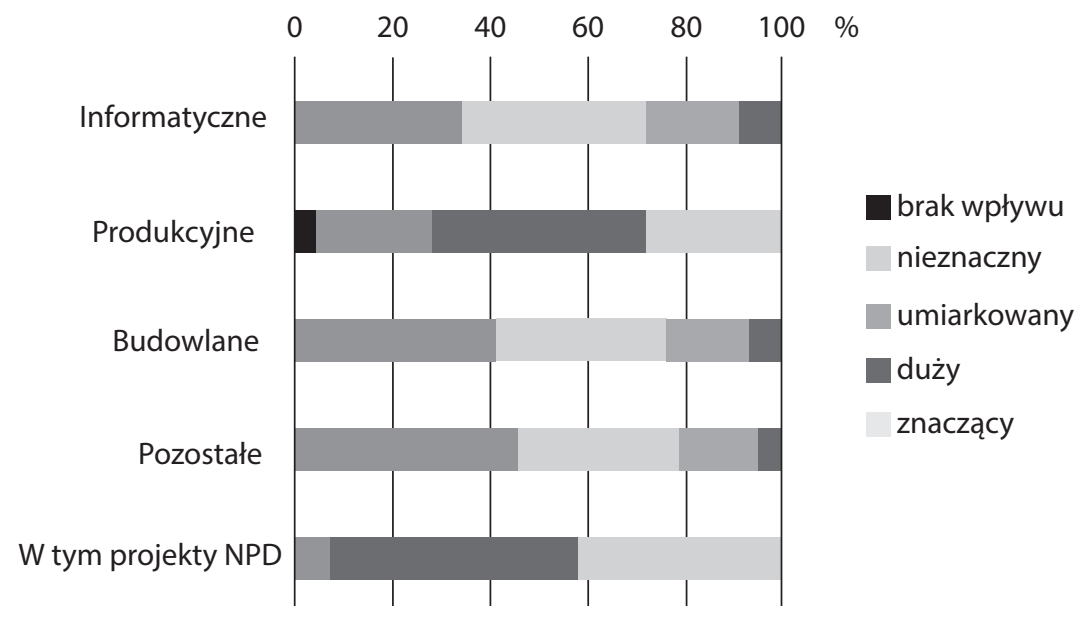

Rysunek 3. Wpływ technologii związanych z Przemysłem 4.0 na działalność projektową według typu projektu, z uwzględnieniem podtypu projektów NPD

Źródto: badania własne.

Zdecydowanie większe zróżnicowanie w odpowiedziach w zależności od typu projektu zaobserwowano dla technologii związanych z Przemysłem 4.0 (rysunek 3). Największy wpływ technologie T-4.0 miały na projekty produkcyjne - sięgał on średnio wartości 4 . Na zbliżonym poziomie był wpływ na projekty informatyczne, budowlane oraz pozostałe - odpowiednio: 2,0, 1,9 oraz 1,8. Ta różnica została jeszcze bardziej uwydatniona przy porównaniu sumarycznych wskazań 
dużego i znacznego wpływu technologii T-4.0 na działalność projektową w zależności od typu projektu. Aż w 72\% przypadków wskazania te dotyczyły projektów produkcyjnych (w tym dla projektów NPD było to aż 93\%).

W wyniku przeprowadzonych badań uzyskano też informacje o wiedzy respondentów dotyczącej sposobu, w jaki nowoczesne technologie wpływają na poszczególne obszary działalności projektowej (tabela 3). W prawie dziewięciu przypadkach na dziesięć respondenci nie potrafili określić, jaki jest sposób wpływu technologii T-4.0, podczas gdy dla związanych z mediami społecznościowymi było to sześć na dziesięć osób, a dla pozostałych technologii zaledwie 12\%.

Tabela 3. Brak wiedzy o sposobie wpływu poszczególnych technologii na obszary działalności projektowej

\begin{tabular}{|l|c|c|}
\hline \multicolumn{1}{|c|}{ Rodzaj technologii } & Liczba* $^{*}$ & Procent \\
\hline Technologie 4.0 & 240 & $91 \%$ \\
\hline Technologie MS & 174 & $66 \%$ \\
\hline Pozostałe & 32 & $12 \%$ \\
\hline
\end{tabular}

* Respondenci mogli wskazać więcej niż jedną odpowiedź. Źródto: badania własne.

\section{Dyskusja}

Wśród wielu nowoczesnych technologii będących źródłem wyzwań dla organizacji rozróżnić należy takie, które zostały już rozpoznane, organizacje wypracowały sposoby podejmowanych działań i obecnie są one tylko udoskonalane, oraz takie, co do których organizacje poszukują w dalszym ciągu rozwiązań. Do tych ostatnich zaliczyć należy technologie związane z mediami społecznościowymi oraz Przemysłem 4.0, które zostały zidentyfikowane w wyniku przeprowadzonych badań jako mogące implikować szczególne wyzwania dla zarządzania projektami w organizacjach.

\section{Media spotecznościowe}

Media społecznościowe stanowią innowacje technologiczne (zarówno pod względem sprzętu komputerowego, jak i oprogramowania), które ułatwiają tworzenie i wymianę treści w czasie rzeczywistym oraz interakcję użytkowników podłączonych do internetu ${ }^{18}$. Można je również zdefiniować jako kanały informacyjne

18 E. Bonson i wsp., Local E-Government 2.0: Social Media and Corporate Transparency in Municipalities, „Government Information Quarterly” 2012, vol. 29, no. 2, s. 123-132. 
umożliwiające interakcję między użytkownikami (wymiana informacji, wiedzy, wyrażanie opinii, komentarzy itp. ${ }^{19}$. Media społecznościowe obejmują przykładowo wspólne projekty (np. Wikipedia), blogi, społeczności tworzone przez użytkowników (np. YouTube), serwisy społecznościowe (np. Twitter), wirtualne światy gier (np. EverQuest) i wirtualne światy społecznościowe (np. Second Life).

Media społecznościowe to nowa rzeczywistość w świecie pracy, która stanowi szczególne wyzwanie dla organizacji i kierowników projektów ${ }^{20}$, ponieważ powoduje, że znikają bariery oddzielające sferę zawodową od prywatnej. Pracownicy coraz częściej są w stanie gotowości do ciągłego komunikowania spraw związanych z pracą oraz życiem prywatnym za pomocą nowych technologii. Organizacje powinny zatem być świadome wyzwań, jakie niosą ze sobą te technologie.

Wyniki przeprowadzonych badań pokazały, że wyzwania technologiczne związane z mediami społecznościowymi, aczkolwiek znaczące, w niewielkim stopniu są uzależnione od typu projektu. Ukazały również, że istnieje średniowysoki poziom niewiedzy dotyczącej sposobu, w jaki te wyzwania wpływają na poszczególne obszary działalności projektowej.

\section{Przemyst 4.0}

Koncepcja Przemysłu 4.0 została nakreślona podczas targów naukowo-technicznych w Hanowerze w 2011 roku ${ }^{21}$. U jej podstaw leżał gwałtowny rozwój technologiczny związany z nowymi możliwościami gromadzenia, przetwarzania i wykorzystania danych oraz z dalszym upowszechnieniem automatyzacji procesów produkcyjnych. Szczególnie burzliwy rozwój można było zaobserwować w kontekście Internetu rzeczy (Internet of Things - IoT), możliwości przetwarzania dużych zbiorów danych (Big Data), przetwarzania w chmurze (Cloud Computing) oraz związanej z nimi analizy danych (Data Analytics), opartej niejednokrotnie na procesach wykorzystujących sztuczną inteligencję (Deep Learing) ${ }^{22}$. Powstały nowe możliwości produkcyjne, jakie daje wytwarzanie addytywne, czy też systemy

19 A.M. Kaplan, M. Haenlein, Users of the World, Unite! The Challenges and Opportunities of Social Media, „Business Horizons” 2010, vol. 53, no. 1, s. 59-68.

20 E. Jędrych, Wykorzystanie mediów społecznościowych w zarządzaniu pracownikami w organizacjach gospodarczych, „Zeszyty Naukowe Uczelni Vistula” 2015, z. 44(6) „Ekonomia IX. Kształtowanie wizerunku pracodawcy", s. 120-132.

21 H. Kagermann, W. Wahlster, J. Helbig, Recommendations for Implementing the Strategic Initiative Industrie 4.0., ACATECH - National Academy of Science and Engineering, Frankfurt/ Main 2013.

22 Y. Wang, Development of an Energy Management System Using 'Big Data' and 'Wireless' Technologies for Industrie 4.0 in Brewery Industry, ,International Journal of Simulation: Systems, Science and Technology" 2015, vol. 16.2A, s. 101-104. 
cyberfizyczne (Cyber Physical Systems - CPS) ${ }^{23}$. Warto zauważyć, że rozwój w poszczególnych obszarach był w dużym stopniu zdeterminowany dostępem do internetu już nie tylko na poziomie organizacji, jej komórek, pracowników i kooperantów, ale również w warstwie fizycznej urządzeń wytwórczych. W związku z tym możliwe było rozszerzenie zastosowań w organizacjach rzeczywistości wirtualnej (Virtual Reality) ${ }^{24}$, symulacji i rozszerzonej rzeczywistości (Augmented Reality) ${ }^{25}$. Na bazie powyższych możliwości coraz częściej organizacje zaczęły podejmować próby budowania swoich wirtualnych odpowiedników, określanych jako cyfrowe bliźniaki (Digital Twins) ${ }^{26}$. W ten sposób uzyskały możliwość szybkiego symulowania zmian, bez konieczności ponoszenia znaczących kosztów inwestycyjnych oraz wydłużonego czasu oczekiwania na rezultaty w świecie rzeczywistym.

Należy nadmienić, że szybkość postępu technologicznego w Przemyśle 4.0 jest w bardzo dużym stopniu uzależniona od powszechności i jakości dostępu do internetu. Dlatego też dalszy rozwój sieci światłowodowych, bezprzewodowych o dużej przepustowości czy też sieci komórkowych piątej generacji będzie determinował upowszechnianie się technologii związanych z Przemysłem 4.0 w organizacjach ${ }^{27}$.

W wyniku przeprowadzonych badań można skonstatować, że technologie związane z Przemysłem 4.0 stanowią w dużej mierze niewiadomą, jeśli chodzi o wyzwania, jakie niosą dla poszczególnych obszarów działalności projektowej. Ta obserwacja jest szczególnie istotna w kontekście bardzo wysokiego wpływu na działalność projektową, szczególnie dla branży produkcyjnej. Wyniki dla niej uzyskane, ze szczególnym uwzględnieniem projektów mających na celu rozwój nowych produktów, znacząco odbiegają od wyników otrzymanych z pozostałych sektorów. To bardzo ważny wniosek, gdyż nowe technologie związane z Przemysłem 4.0 podlegają ciągłemu upowszechnianiu w organizacjach na całym świecie.

23 G.D. Putnik i wsp., What Is a Cyber-Physical System: Definitions and Models Spectrum, „Fme Transactions" 2019, vol. 47, no. 4, s. 663-674.

24 J. Du i wsp., Covr: Cloud-Based Multiuser Virtual Reality Headset System for Project Communication of Remote Users, „Journal of Construction Engineering and Management” 2018, vol. 144, no. 2, s. 1-19.

25 L. Ardito i wsp., Towards Industry 4.0 Mapping Digital Technologies for Supply Chain Management-Marketing Integration, „Business Process Management Journal” 2019, vol. 25, no. 2, s. 323-346.

26 H. Ahuett-Garza, T. Kurfess, A Brief Discussion on the Trends of Habilitating Technologies for Industry 4.0 and Smart Manufacturing, „Manufacturing Letters” 2018, no. 15, s. 60-63.

27 V. Salehi, Development of an Agile Concept for Mbse for Future Digital Products through the Entire Life Cycle Management Called Munich Agile Mbse Concept (Magic), „Computer-Aided Design and Applications" 2020, vol. 17, no. 1, s. 147-166. 


\section{Podsumowanie}

W wyniku przeprowadzonych badań stwierdzono, że obecnie wśród największych wyzwań technologicznych należy wyróżnić te związane z mediami społecznościowymi i Przemysłem 4.0. Jakkolwiek ich źródła są odmienne, to - jak pokazały wyniki badań - stanowią one dla organizacji znaczne wyzwanie w obszarze zarządzania projektami. Szczególnie wysoki poziom niewiedzy respondentów w odniesieniu do wpływu technologii związanych z Przemysłem 4.0 na poszczególne obszary zarządzania projektami wskazuje na pilną potrzebę zapełnienia tej luki wiedzy.

Mając świadomość stosunkowo nielicznej próby badawczej i wynikających z tego ograniczeń, trudno dokonywać uogólnień otrzymanych wyników dotyczących całej zbiorowości. Jednakże wyniki przeprowadzonych badań pozwalają wskazać obszary, w których mógłby zostać podjęty dalszy wysiłek badawczy. Jednym z nich jest niewątpliwie Przemysł 4.0 i wpływ technologii z nim związanych na poszczególne obszary zarządzania projektami. Kolejny wątek badawczy mógłby zostać podjęty w relacji mediów społecznościowych i zarządzania projektami, chociażby w kontekście pracy zespołów projektowych.

Bibliografia

Ahsan M.J.F.F., Herath S.K., Adoption of E-Commerce in Small and Medium Enterprises: With Special Reference to the Sri Lanka-Based Apparel Industry, „International Journal of Management and Enterprise Development" 2006, vol. 3, no. 6, s. 579-598.

Ahuett-Garza H., Kurfess T., A Brief Discussion on the Trends of Habilitating Technologies for Industry 4.0 and Smart Manufacturing, „Manufacturing Letters” 2018, no. 15, s. 60-63.

Alharthi A., Krotov V., Bowman M., Addressing Barriers to Big Data, „Business Horizons” 2017, vol. 60, no. 3, s. 285-292.

Ardito L., Messeni Petruzzelli A., Panniello U., Garavelli A.C., Towards Industry 4.0 Mapping Digital Technologies for Supply Chain Management-Marketing Integration, „Business Process Management Journal" 2019, vol. 25, no. 2, s. 323-346.

Besner C., Hobbs B., Discriminating Contexts and Project Management Best Practices on Innovative and Noninnovative Projects, „Project Management Journal” 2008, no. 39, s. S123-S134.

Bonson E., Torres L., Royo S., Flores F., Local E-Government 2.0: Social Media and Corporate Transparency in Municipalities, „Government Information Quarterly” 2012, vol. 29, no. 2, s. $123-132$.

Bordley R.F., Keisler J.M., Logan T. M., Managing Projects with Uncertain Deadlines, „European Journal of Operational Research" 2019, vol. 274, no. 1, s. 291-302.

Cabała P. (red)., Metody doskonalenia procesów zarzq̨dzania projektami w organizacji, Wydawnictwo Difin, Warszawa 2016.

Cyfert S., Strategiczna odnowa przedsiębiorstwa, [w:] G. Bełz, S. Cyfert (red.), Strategiczna i organizacyjna odnowa przedsiębiorstwa, Wydawnictwo Uniwersytetu Ekonomicznego we Wrocławiu, Wroctaw 2017, s. 19-34. 
Dolata M., The Sources of Competitive Advantage from the Perspective of Project Management - Results of Empirical Studies, „Management-Poland” 2019, vol. 23, no. 1, s. 75-89.

Du J., Shi Y., Zou Z., Zhao D., Covr: Cloud-Based Multiuser Virtual Reality Headset System for Project Communication of Remote Users, „Journal of Construction Engineering and Management" 2018, vol. 144, no. 2, s. 1-19.

Jędrych E., Wykorzystanie mediów społecznościowych w zarzqdzaniu pracownikami w organizacjach gospodarczych, „Zeszyty Naukowe Uczelni Vistula” 2015, z. 44(6) „Ekonomia IX. Kształtowanie wizerunku pracodawcy", s. 120-132.

Kagermann H., Wahlster W., Helbig J., Recommendations for Implementing the Strategic Initiative Industrie 4.0., ACATECH - National Academy of Science and Engineering, Frankfurt/Main 2013.

Kang Y., O'Brien W.J., Mulva S.P., Value of It: Indirect Impact of It on Construction Project Performance Via Best Practices, „Automation in Construction” 2013, no. 35, s. 383-396.

Kaplan A.M., Haenlein M., Users of the World, Unite! The Challenges and Opportunities of Social Media, „Business Horizons” 2010, vol. 53, no. 1, s. 59-68.

Kim K., Garza J.M. de la, Evaluation of the Resource-Constrained Critical Path Method Algorithms, „Journal of Construction Engineering and Management-Asce” 2005, vol. 131, no. 5, s. 522-532.

Liu J., Wei F., The Application of Project Management in Aero-Engine Developing Project, [w:] H. Wang, K. Takahashi (red.), ICIM2012: Proceedings of the Eleventh International Conference on Industrial Management, Japan Industrial Management Association, Tokyo 2012, s. $245-248$.

Nguyen T.H.D., Chileshe N., Rameezdeen R., Wood A., External Stakeholder Strategic Actions in Projects: A Multi-Case Study, „International Journal of Project Management” 2019, vol. 37, no. 1 , s. 176-191.

Putnik G.D., Ferreira L., Lopes N., Putnik Z., What Is a Cyber-Physical System: Definitions and Models Spectrum, „Fme Transactions” 2019, vol. 47, no. 4, s. 663-674.

Romanowska M., Effectiveness of Reorganization of an Enterprise Operating in a Globalized Sector, „Transformations in Business and Economics” 2009, vol. 8, no. 3, suppl. B, s. 83-93.

Salehi V., Development of an Agile Concept for Mbse for Future Digital Products through the Entire Life Cycle Management Called Munich Agile Mbse Concept (Magic), „Computer-Aided Design and Applications" 2020, vol. 17, no. 1, s. 147-166.

Spałek S., Dojrzałość przedsiębiorstwa w zarzq̨dzaniu projektami, Wydawnictwo Politechniki Śląskiej, Gliwice 2013.

Spatek S., Traditional vs. Modern Project Management Methods. Theory and Practice, „Smart and Efficient Economy: Preparation for the Future Innovative Economy" 2016, s. 499-506.

Stabryła A. (red.), Doskonalenie struktur organizacyjnych przedsiębiorstw w gospodarce opartej na wiedzy, Wydawnictwo C.H. Beck, Warszawa 2009.

Trocki M., Miejsce i rola projektów w zarzq̨dzaniu, [w:] M. Trocki (red.), Społeczna odpowiedzialność działalności projektowej, Oficyna Wydawnicza SGH - Szkoła Główna Handlowa w Warszawie, Warszawa 2019, s. 9-21.

Vadhanasin V., Ratanakuakangwan S., Santivejkul K., Social Media in Project Communication Management - a Conceptual Framework, „Advanced Science Letters” 2017, vol. 23, no. 1, s. 581-584.

Wang Y., Development of an Energy Management System Using 'Big Data' and 'Wireless' Technologies for Industrie 4.0 in Brewery Industry, ,International Journal of Simulation: Systems, Science and Technology" 2015, vol. 16.2A, s. 101-104.

Wauters M., Vanhoucke M., A Comparative Study of Artificial Intelligence Methods for Project Duration Forecasting, „Expert Systems with Applications” 2016, no. 46, s. 249-261.

Wyrozębski P., Biuro zarządzania projektami, Polskie Wydawnictwo Ekonomiczne, Warszawa 2019. 
Wysocki K.R., McGary R., Efektywne zarządzanie projektami, Wydawnictwo Helion, Gliwice 2005.

\section{Streszczenie}

Wyzwania technologiczne niejednokrotnie wpływały na rozwój zarządzania projektami w organizacjach, stanowiąc problematykę badawczą podejmowaną przez ośrodki naukowe $\mathrm{z}$ różnych krajów. Szczególnie teraz, wraz z niespotykanym dotychczas przyspieszeniem w upowszechnianiu się nowych technologii, kontynuacja badań w tej tematyce staje się niezwykle ważna i aktualna. Celem artykułu jest próba odpowiedzi na pytanie: „Które ze współczesnych technologii mogą implikować szczególne wyzwania dla zarządzania projektami w organizacjach?”. Aby uzyskać na nie odpowiedź, przeprowadzono międzynarodowe, empiryczne badania ilościowe z wykorzystaniem kwestionariuszy ankietowych. W efekcie otrzymano odpowiedzi od 264 respondentów. Analiza wyników pozwoliła na zidentyfikowanie technologii związanych z Przemysłem 4.0 oraz mediami społecznościowymi jako stanowiących obecnie największe wyzwania dla zarządzania projektami w organizacjach.

Słowa kluczowe: zarządzanie projektami, Przemysł 4.0, media społecznościowe, wiedza, wpływ, organizacja, wyzwanie

\section{Technological challenges and project management in organizations}

\section{Abstract}

Technological challenges have often influenced the development of project management in organizations, and have been the subject of research undertaken by academics from various countries. Particularly nowadays, with the unprecedented acceleration in the dissemination of new technologies, the continuation of research on this topic is becoming ever more important importance. The purpose of the article is to try to answer the question: "Which of the contemporary technologies may poses particular challenges for project management in organizations?". To obtain the answer, international, empirical, quantitative, questionnaire-based research was conducted. Within the study answers were received from 264 respondents. Analysis of the results allowed the identification of technologies related to Industry 4.0 and social media as currently representing the greatest challenges for project management in organizations.

Keywords: project management, Industry 4.0, social media, knowledge, influence, organization, challenge 